\title{
Energy Research Infrastructures in Europe and Beyond: Mapping an Unmapped Landscape
}

\section{Mikkel Stein Knudsen}

Finland Futures Research Centre, Turku School of Economics, University of Turku

\section{Marianna Birmoser Ferreira-Aulu}

Finland Futures Research Centre, Turku School of Economics, University of Turku

\section{Jari Kaivo-oja}

Finland Futures Research Centre, Turku School of Economics, University of Turku

\section{Jyrki Luukkanen}

Finland Futures Research Centre, Turku School of Economics, University of Turku

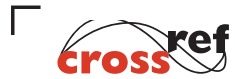

http://dx.doi.org/10.5755/j01.eis.1.15.28840
EIS $15 / 2021$

Energy Research Infrastructures in Europe and Beyond: Mapping an Unmapped Landscape

Submitted 02/2021

Accepted for publication $06 / 2021$
European research and innovation policy highlights the importance of transnational scientific collaboration, International collaborations in science concentrates and magnifies resources for conducting research and foster innovation. Often, individual institutions, or even individual European countries, cannot provide the right capabilities by themselves. Joint facilities and Research Infrastructures (RIs) are therefore of high importance, and through Horizon 2020 and Horizon Europe nearly $€ 5$ bn EU funding is set aside for these institutions.

Considering the large-scale funding and the perceived importance of Rls, a better understanding of their roles, functions, and usefulness is highly relevant to of European integration studies. While 'Research Infrastructures' has become a fixed terminology of EU-policy, conceptually defining RIs remain a matter of academic debate. We contribute to the "what is an RI?"-discussion by synthesizing existing literature and presenting novel empirical data from the energy domain mapping of the Horizon 2020-project Research Infrastructures in the International Landscape (RISCAPE).

We provide insights into the process of mapping an hitherto largely unknown landscape of global Energy RIs. These insights touch upon both definitional issues relevant to the Rl-field and methodological concerns for future landscape analyses. Finally, the article suggests that when it comes to energy research, RI-terminology might be misplaced as a catchall modern synonym for "gold standard world-class science".

KEYWORDS: Research Infrastructures (RI), energy research, landscape analysis, European science policy, Horizon Europe, Europeanisation, Horizon Europe.

Research Infrastructures (RIs) are receiving increasing attention in the political organization of science- and innovation systems. This is particularly true at the level of the European Union, where some even talk of a 'political hype around RIs' (Hallonsten, 2020). The argumentative logic behind the hype is such that modern scientific advancements require facilities and investments beyond the capabilities of individual organizations, beyond even the capabilities of individual European countries. "Multinational collaboration in large-and mid-scale research infrastructure (RI) is increasingly essential, as cutting-edge research requires costly and sophisticated instrumentation and national governments face financial constraints" (Moskovko \& Teich, 2020). By pooling

\section{Abstract}

\section{Introduction}

\section{ktu}

European Integration Studies No. $15 / 2021$, pp. 111-124 doi.org/10.5755/01. eis.1.15.28840 
European resources, the European scientific community attains necessary capabilities, which would otherwise be impossible to reach.

Rls provide more or less the perfect marriage of narratives for a European Science, Technology, and Innovation (STI)-policy dominated by the simultaneous and linked forces of globalization and accountability (Elzinga, 2012). Research, technological development, and innovation policy has become the second-largest Europeanized policy area in budgetary terms (Biegelbauer \& Weber, 2018), and RIs fit nicely within dominant policy frames of "Europe as Laggard" and "Grand challenges" (Biegelbauer \& Weber, 2018; Ryan, 2015). "Tackling grand challenges" is now a ubiquitous frame in science and politics (Kaldewey, 2018), lending further legitimacy to the concept of Research Infrastructures: Topics tackled by science today are so 'grand' that no one can go at it alone.

An economic logic for Research Infrastructures is also put forward. They are considered as a strategic 'pillar' and an 'engine of growth' (Moskovko et al., 2019), and they are hailed as transformative (European Commission, 2020). They are also recipients of significant amounts of European funding. Budgets for Research Infrastructures ran up to $€ 1.7$ billion in the $7^{\text {th }}$ Framework Programme for Research and Technological Development (FP7, 2007-2013), and € 2.48 billion in the Horizon 2020 Framework Programme (2014-2020) (European Commission, 2020). Similar amounts of funding are expected for the new Horizon Europe-programme (2021-2027).

Despite strong political prioritization and the considerable economic budgets, academic attention for Rls has been lagging. Research Infrastructures remain a surprisingly understudied object of interest. Much of the actual published literature on Rls thus stems from authors and co-authors themselves involved in Rls. A majority of the academic RI literature is, therefore, in this sense, the story as told by the RI community itself. The other key source of RI literature has derived from a rather small group of Science- and Technology Studies-scholars with a particular dedication to the field. However, with, in relative terms, a wealth of new publications (see e.g. Cramer \& Hallonsten, 2020; Cramer, 2020; Beck \& Charitos, 2021), more neutral/critical reflections have probably been published within the last few years than in the entire preceding period.

This article is somewhat of a hybrid between the internal RI/external STS-outset identified in the existing literature. It is born out of the Horizon 2020-funded project Research Infrastructures in the International Landscape (RISCAPE), which ran three years from 2017-2019 intending to map international RI-landscapes across eight different scientific fields. The project funding was part of the targeted European funds for Rls, and a majority of the consortium had direct ties to existing RIs. The authors of this article contributed with the analysis of the energy research domain, without any formal ties to Research Infrastructures (a reflection in part of the lack of previous coordination within the European energy RI landscape in comparison to within other scientific disciplines).

The basic value proposition of the project was to illuminate a previously unknown aspect of RIs of central importance to the development of European policy, namely which Research Infrastructures exist outside the EU? Before this mapping exercise, Research Infrastructures have been held up as a necessity for Europe to succeed in the global scientific competition, but the identification and contribution of similar organizations elsewhere have been, essentially, a blind spot. Little has been known about outside organizations, what kind of features these organizations embody, and what the potential would be for shared collaborations to the benefit of European researchers. Since literally billions are devoted to ensuring European institutions can compare themselves favorably with others, this lack of knowledge is problematic. Similarly, potentially allocating large-scale funding only to replicate similar facilities elsewhere may not be the best use of public funds. The motivation for providing a mapping of this unmapped landscape of non-EU Research Infrastructures was therefore clear. The research methodology for the mapping exercise, and therefore for this article, was primarily based on qualitative, semi-structured interviews 
with international Rls supplemented by data gathering through field- and desktop research.

The results of this mapping exercise are available in the final project report (Asmi et al., 2019) and through extensive domain mapping reports (all publicly available through the project website, www.riscape.eu). For this reason, this article focuses less on the outcomes, but instead concerns some of the key steps needed to perform this mapping of an unmapped Energy Research Infrastructures-landscape:

i How can a globally relevant Research Infrastructure be defined?

ii What constitutes an 'energy research Rl'?

iii Which organizational aspects should be mapped?

iv What kind of potential for internationalization of RIs can be identified?

v How could future mapping exercises be improved methodologically?

By answering these questions, we provide insights on how the field of RIs can be mapped, and we simultaneously contribute to the emerging academic discussion on Research Infrastructures. Our study also provides sparks for the discussion on whether scientific contributions scale with size (cf. D'Ippolito \& Rüling, 2019) or not (cf. Fortin \& Currie, 2013). The findings suggest that at least for the energy research domain, ascribing STI-primacy to Research Infrastructures as a 'modern gold standard' of science disproportionally benefits certain types of institutions, perhaps at the expense of the majority of the field.

In other words, the article presents how the collection of information to the RISCAPE-project was done and reflects upon the process of the project itself. This guides us to suggest solutions for the challenges we faced, and which we believe might be emblematic of any attempt to map Research Infrastructures, at least within the energy research domain. The study, therefore, provides empirical novelty with an overview of Energy RIs and general insights for the emerging RI literature. Our study also provides sparks for the discussion on whether scientific contributions scale with size (cf. D'Ippolito \& Rüling, 2019) or not (cf. Fortin \& Currie, 2013). The findings suggest that at least for the energy research domain, ascribing STI-primacy to Research Infrastructures as a 'modern gold standard' of science disproportionally benefits certain types of institutions. This could very well be at the expense of the majority of the field if funding allocation follows a political RI-prioritization. At the end of the article, we also use the project process experiences to suggest alternative ways for future mapping projects.

The article first situates Research Infrastructures in the context of European integration. This is followed by a section on data, methods, and the RISCAPE-project. The main analytical section is structured by the five mapping elements described above. Finally, the article is concluded with a conclusion.

The historical development of scientific cooperation in Europe and the establishment of common research organizations and research facilities has been well documented in the STI literature (see e.g. Cramer et al., 2020; Hallonsten, 2012, 2014b; Papon, 2004, 2009). This development is tightly interwoven with the establishment of post-war intergovernmental collaboration in Europe on the one hand, and the Cold War advancement of "Big Science" competition in e.g. nuclear physics on the other. The launch of the European Organization for Nuclear Research (CERN) - to this day, perhaps the most prominent Research Infrastructure in Europe - in the 1950s was Europe's first postwar experience in large-scale cooperation (Cramer et al., 2020). It is worth noting also that there is an element of anachronisms here; terms such as Research Infrastructure or similar colloquial terms such as "Big Science" or "Megascience" were not used at the time, but instead, they are applied retrospectively to previously established institutions.

Research Infrastructures in European Integration 
After an early enthusiasm, interest in shared European facilities waned over the next decades. This is not necessarily a unique European story. Our RISCAPE-analysis shows that many international energy Rls were similarly established in the period between 1945 and 1960 - and only very few in the decades following that. Still, a considerable chunk of the available academic RI literature is essentially a Europe-focused retelling of post-war historical geopolitics, and then of the later dilemmas faced on the bumpy road towards increased European integration. The actual scientific relevance of the facilities often takes sidestep in this literature to the roles played by diplomacy in establishing them, and to their role in establishing diplomatic cooperation in return.

Viewed through this historical lens research organizations, nominally purely about science, are mired by complexity, "deeply embedded in (geo)politics and characterised by the same horse-trading as the jigsaw puzzle of political agreements that make up the European Union." (Hallonsten, 2012). In retrospect, every major collaborative effort was conceived and established on an ad hoc-basis, and new shapes and forms emerged for every new project. Final decisions on any project are made at the highest political level, and decades of establishing and not-establishing facilities reflected developing high-politics trends. This is not just a thing of the past, but something that seemingly continues to this day. National participation in projects, such as the example of Russia participating in the European XFEL-project, is still seen as "the pursuit of [their] interests by other means" (Hallonsten, 2014b). The participation agreement has been characterized as a much-needed symbolic act of unity in an otherwise 'cold encounter' of the German Chancellor Merkel and Russian President Putin in a 2007 high-level summit.

Over the past 15 years, a distinct terminological and legal framework has developed around RIs in the European STI-policy landscape. This includes the introduction of formal institutions such as The European Strategy Forum for Research Infrastructures (ESFRI) and European Research Infrastructure Consortiums (ERIC). The European Strategy Forum for Research Infrastructures provides a bi- or triannual roadmap of ESFRI Projects, which are new RIs in progress towards implementation, and ESFRI Landmarks, which are successfully implemented RIs. Established Rls are (sometimes, although not always) organized with the unique legal framework of a European Research Infrastructure Consortium (ERIC) (Lindstrøm \& Kropp, 2017; Moskovko et al., 2019; Ryan, 2019; Moskovko, 2020).

Untangling the development of Research Infrastructures in Europe from political processes of European integration is difficult. The "concept of R/s has a political origin and apparent political usefulness (...) it was most likely invented by EU policymakers for political purposes" (Hallonsten, 2020). A critical examination of European RI policy might raise the question of whether increased prioritization of RIs is a necessary function of a desire for Europeanization of science, or whether increased Europeanization is a necessary result of changing scientific needs. Both statements probably have some truth to them.

As the XFEL-case highlights, Rls' function in European integration processes is thus not limited to science itself, but also helpful for science diplomacy. By showcasing attractive access to large-scale European research activities, EU RIs can be a useful tool for EU external foreign policy (for literature on Rl's science policy function, see Moedas, 2016; Flatten, 2018; Moskovko \& Teich, 2020; for EU's external engagement in science and research, see e.g. Prange-Gstöhl, 2017, 2019). European stakeholders have also attempted to upload the RI-concept to a wider international level - to some success. The OECD Global Science Forum (GSF) has adopted the term (OECD, 2017), co-opting the previous Megascience Forum established in 1992. The Group of Senior Officials under the G7/G8 has done significant work in advancing RIs (GSO, 2017). Countries such as Australia and South Africa have also published national Research Infrastructure roadmaps in the European vein within recent years. Academic literature on non-European Rls is 
also sparse, although there are notable exceptions related to at least China (Qiao et al., 2016; Xu et al., 2017) and Brazil (Caliari et al., 2020).

RISCAPE can, as an international mapping funded by the European Commission after an initial call process, be seen as another means of extending the European scientific and diplomatic footprint outside the European region.

This study and its data are based on the RISCAPE-project, which maps the non-EU RI-landscape across eight scientific fields. From its outset, the project was developed as a complimentary resource to the existing ESFRI landscape analyses (e.g. ESFRI, 2018) of European scientific fields. It was therefore constructed on the assumption that the European landscape is known, and that the onus was on mapping the unknown landscape outside the European Research Area.

Each scientific field has its field-specific characteristics. While RISCAPE strived to have a project-wide systematic and shared methodology, refined through a series of internal project workshops, the mapping also needed to allow for domain-relevant circumstances. The general methodology of the project is visualized in Figure 1. This shows the analytical sequence from identifying an $\mathrm{Rl}$, prioritizing and pre-selecting them against accepted criteria, making contact, gathering information directly from organizations, interpreting the gathered information, and analyzing it in context with the rest of the collected information.

The content, challenges, and results of some of these steps are described in more detail in the next chapter. RISCAPE aimed to collect information mainly through virtual, directed interviews with Rl-representatives based on a specific RISCAPE-questionnaire. The original design of the project research methodology thus heavily emphasized the use of semi-structured in-depth interviews (see e.g Leech, 2002). The project-wide questionnaire consisted of 56 questions (available from the project website), most of which were open-ended. The questionnaire was designed for the interviews to last for about one hour. Since some of the questions related to practical details, these could be prefilled limiting the time needed, and the questionnaire was thus designed so that the interviews themselves could be done in around one hour. However, for our work package the actual interview sessions took up to 3,5 hours to conduct, and the time potential interviewees would need to spend was a major barrier for engagement. In general, organizing the information collection proved to be rather difficult, and methodological adjustments were made

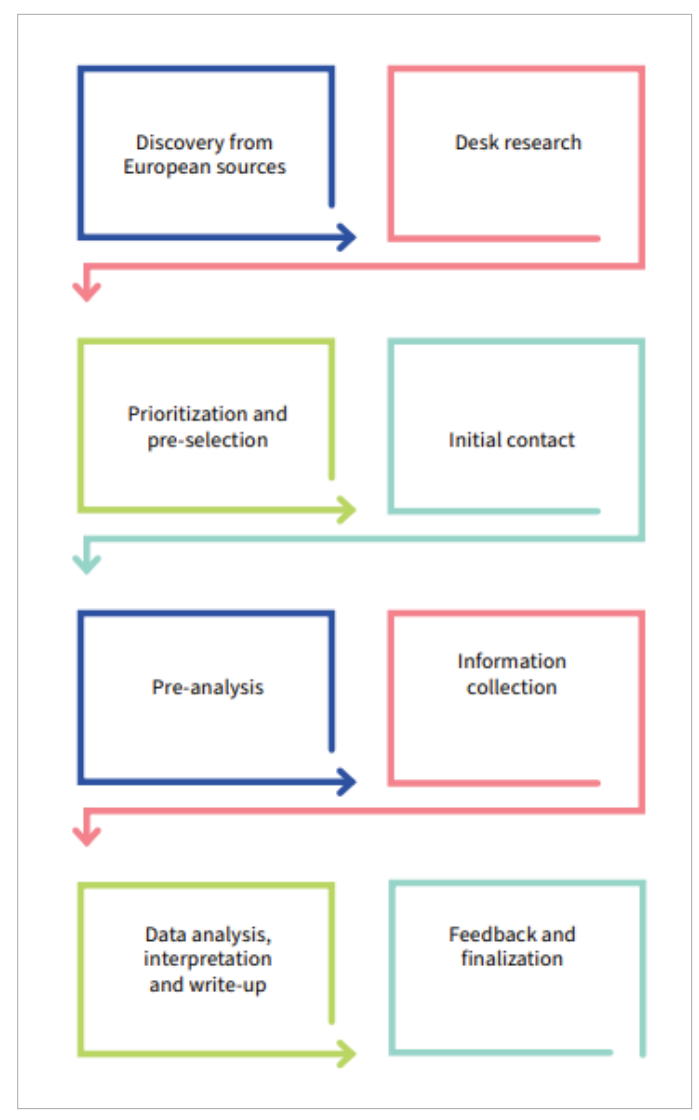

accordingly, cf. chapter 4. Initial information gathering came through utilizing known European sources. For the energy research domain desk research and virtual contacts were supplemented with a stakeholder workshop in Brussels in July 2017 with representatives of European Energy RIs listed on the ESFRI-roadmap or receiving Horizon 2020 Research Infrastructure-funding.
Data and

\section{Methods}

Figure 1

RISCAPE-methodology (Asmi et al., 2019) 


\section{Figure 2}

Identified non-EU Energy Research Infrastructures (Asmi et al., 2019).

\section{Mapping an} unmapped Energy RI-landscape:

Steps, results, and considerations
In total, 37 international Energy RIs were contacted, with 11 of these interviewed with semi-structured interviews. Three of the interviews were conducted face-to-face, while the rest was done through phone- and video meetings. The distribution of the non-EU Energy Research Infrastructures is shown in Figure 2 (the sum of the numbers exceeds 37, due to many Rls being active in more than one energy research subfield).

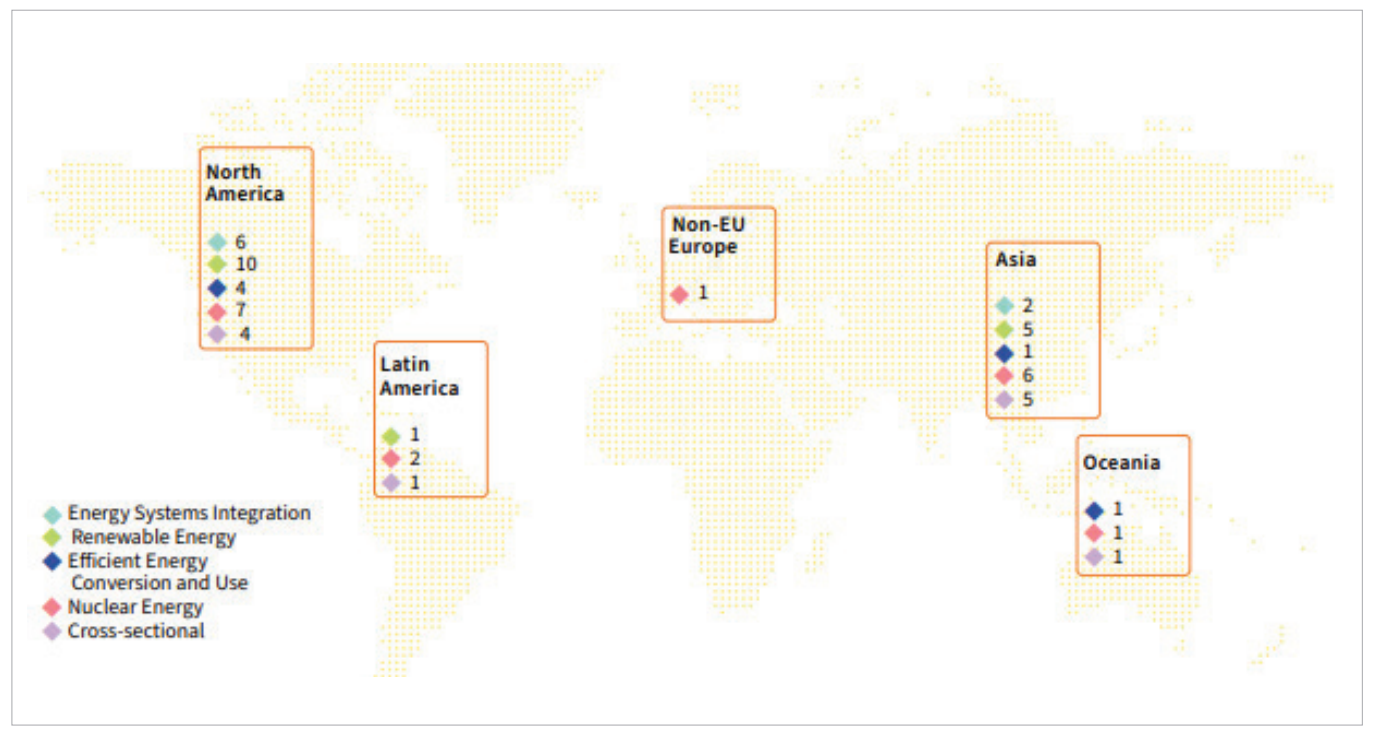

A majority of the identified RIs were located in North America (primarily in the USA) and Asia. The project did not identify any RIs for the final list in neither the ASEAN region nor Africa. This could be a result of initial bias within both researchers and stakeholders approached during the project: RIs tend to pop up on the map in regions, where we knew where to look. While steps were taken to handle this concern, it is hard to conclude, whether the issue was entirely eliminated. One originally identified RI in South Africa was left off the final list for commercial reasons, cf. chapter 4.

This chapter highlights the most important and challenging steps of the mapping process, key results related to the RI-landscape, and considerations with implications for similar exercises in the future.

\section{Defining relevant Research Infrastructures}

The political hype around RIs has not been matched by any comprehensive definitional or categorization work (Hallonsten, 2020). This is perhaps best illustrated by the fact that a total of $60 \mathrm{RIS}$ have appeared on ESFRI-roadmaps, 1042 infrastructures are available in the online MERIL-database (Mapping of the European Research Infrastructure Landscape; MERIL, 2021), while Caliari et al. (2020) identifies no less than 4857 research infrastructures in Brazil alone.

Cramer et al. (2020) suggest a useful differentiation between "research infrastructures" and "Research Infrastructures". Anderson (2013) reminds of the definition of infrastructure in the American Heritage Dictionary as 'the basic facilities, services and installations needed for the functioning of a community or society' (cf. Anderson, 2013). We might say that research infrastructures (non-capitalized) provide functions for a scientific community (a research group, a department, or an institution), while Research Infrastructures provide functions for the (global) scientific community. This is illustrated in figure 3, which was adapted from the South African RI roadmap (Department of Science and Technology, 2016) for the RISCAPE Energy work package. 


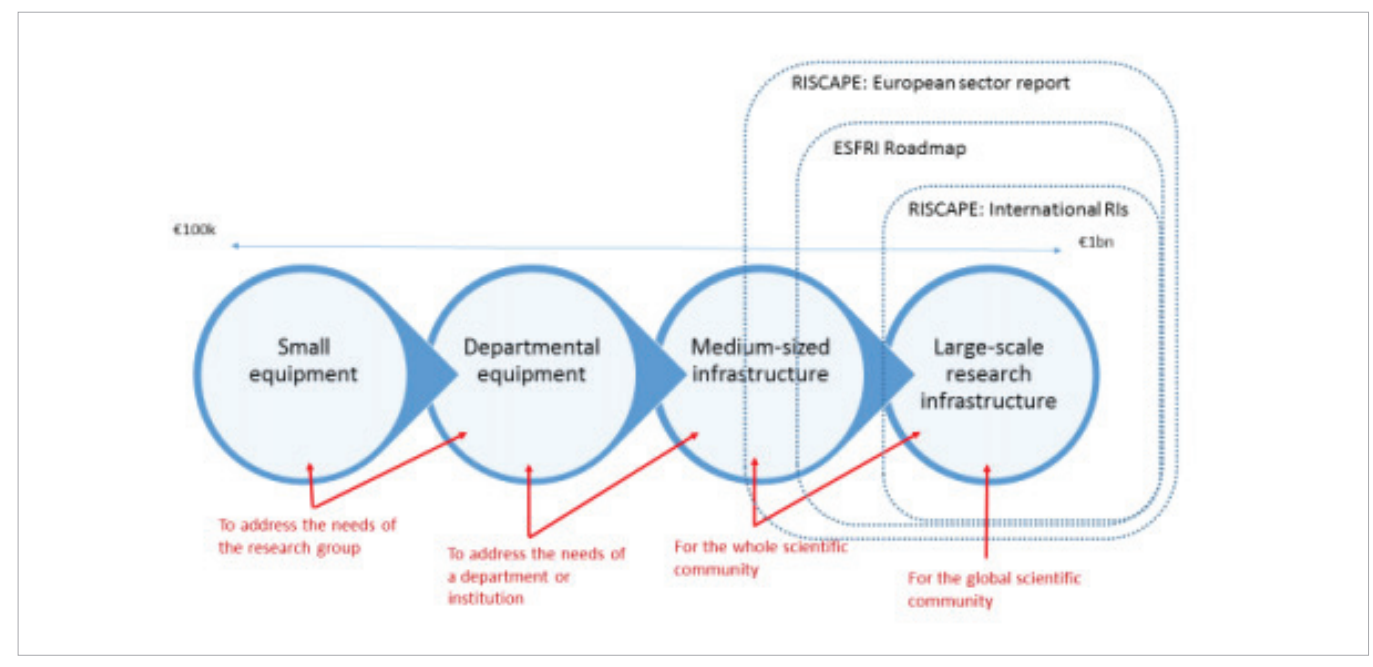

Figure 3

Zooming in on the right Research Infrastructures

International relevance does not in itself make for a meaningful RI-definition, however. For RISCAPE, additional guiding principles were devised through the identification of commonalities between Rl-definitions in previous scientific and policy literature (Asmi et al., 2019). First, Rls are meant for research and science purposes. For an organization to fit the criteria of being an $\mathrm{Rl}$, it is, therefore, a necessary condition that it is concentrated on supporting science.

This may sound self-evident, but it has major implications for mapping the energy RI landscape in the energy sector. Firstly, and perhaps most importantly, it excludes commercial actors for whom research and supporting science is only a secondary goal of the organization. In energy research, private and commercial actors make for a large share of total R\&D spending, yet they don't show up on the RI-landscape when this criterion is applied. Secondly, the line between commercial units and 'real' research entities is often blurred among potential RIs. As an example, nuclear facilities surveyed in RISCAPE enable the pharmaceutical industry with industrial and medical radioisotopes. Supplying rare and valuable products right now is often as important to the organizational narrative of societal impact (and the financing of its activities), as its contributions to long-term scientific advancements. Determining the balancing of dual scientific/ commercial purposes proved to be tricky during the mapping and case-by-case evaluations had to be made. In the end, for example, one research reactor identified by GSO (2017) was left off the map as 'too commercial'. Thirdly, some facilities, especially related to nuclear research, also perform dual balancing acts between serving national security needs and benevolent ideas of supporting the scientific community.

The second guiding principle is that the mapping should not be limited to a universal definition of institutional arrangements. Various RI definitions use different terms such as institution, organization, facilities, resources, and services. However, the distinction also used for the ESFRI-roadmaps between single-sited, distributed and virtual RIs have become commonplace, and these concepts were also used for RISCAPE's mapping. A third guiding principle is the concept of uniqueness used by some of the definitions. Rls, at least those of international interest, must be distinguishable from each other, of a particular nature, or of a particular interest. This is in the vein of the distinction above, namely that capitalized RIs serve the global scientific community. A fourth guiding principle is the suggestion of access. Rls do not, per sé, need to be public organizations, but they should be accessible for public scientists in some form or another and serve a diverse range of users beyond those employed by their own organization. This principle has been less pressed by academic attempts to define the nature of Rls, but it is often integrated into policy considerations of RIs. It is also an explicit feature of the ERIC-regulations (Moskovko et 
Defining Energy

Research and

Energy Research

Infrastructures

Figure 4

Energy RIs Interplay

(ESFRI, 2018) al., 2019). For the mapping of the energy research sector, the national security elements inherent in e.g. nuclear research may complicate this aspect to some extent. A fifth and final guiding principle is longevity. Longevity is often overlooked by existing definitions, but long time horizons are often implicitly assumed in both scientific and policy documents. For mappings such as RISCAPE identifying organizations would also, quite frankly, be slightly pointless, unless the organization was thought to play a role in the future.

The second step of the mapping process was to identify the features of Energy RIs. The ESFRI Strategy Report and Roadmap (ESFRI, 2018) divides the energy domain into five main areas, which themselves comprise several specific fields (illustrated including interrelations in Figure 4). Boundary issues are also challenging. Energy RIs are to a great extent interdisciplinary undertakings (ESFRI, 2018: 48), and RISCAPE identified clear links between Energy Rls and physics (e.g. with nuclear synchrotrons), as well as with health research (nuclear medicine), engineering, and materials research, green chemistry, high-performance computing, and environmental science.

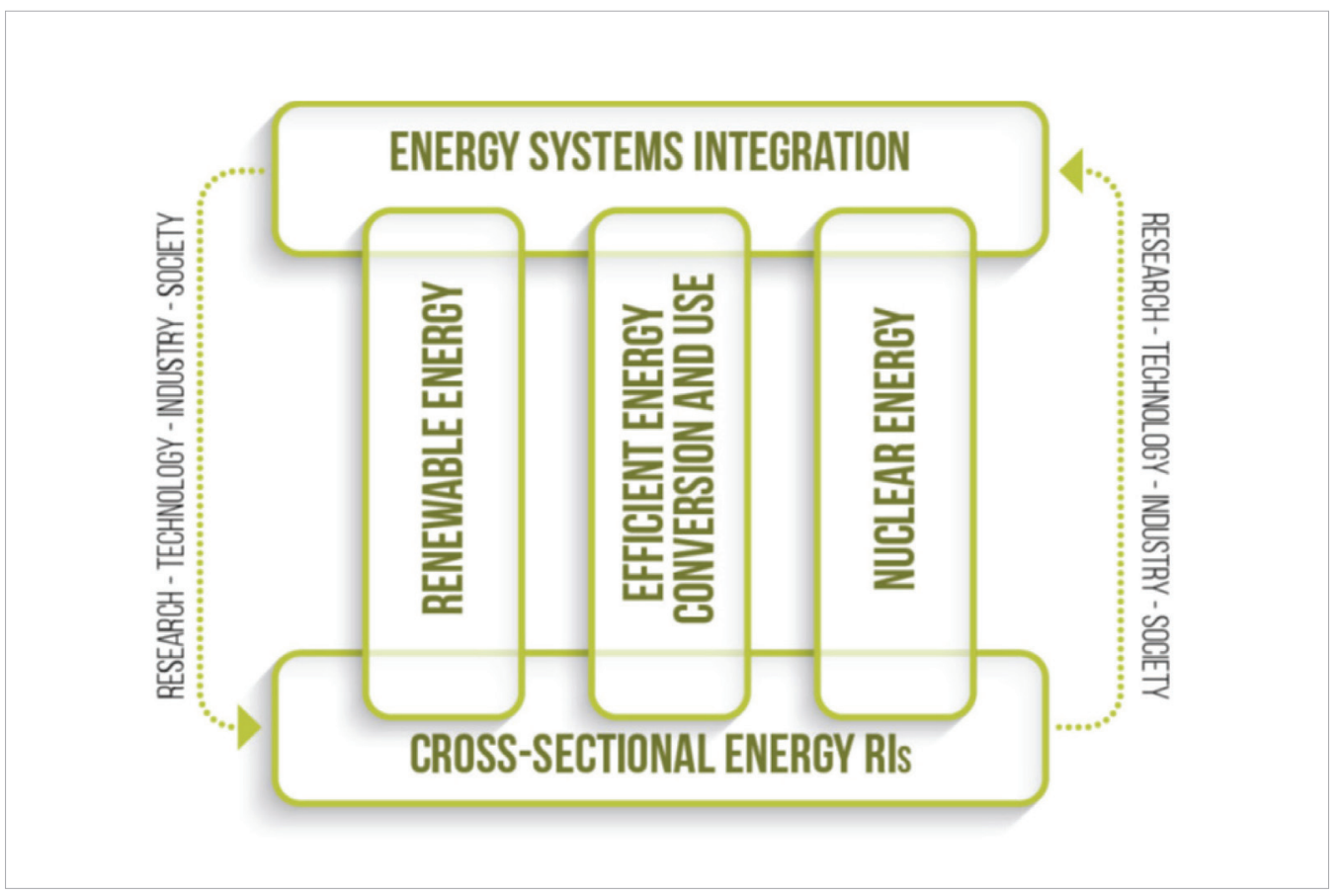

The 2018 ESFRI Roadmap features two ESFRI Landmarks in the energy sector and four ESFRI projects. Jules Horowitz Reactor (JHR) is an experimental reactor facility intended to provide scientific breakthroughs on nuclear fuel and materials. European Carbon Dioxide Capture and Storage Laboratory Infrastructure (ECCSEL) was officially recognized as an ERIC in 2017. Two of the four listed ESFRI-projects are in nuclear research (Multi-purposes hYbrid Research Reactor for High-tech Applications, MYRRHA; International Fusion Materials Irradiation Facility-DEMO Oriented NEutron Source, IFMIF-DONES), while two others are related to renewable energy (European Solar Research Infrastructure for Concentrated Solar Power, EU-SOLARIS, European WindScanner Facility, WindScanner). WindScanner is a distributed RI focused on the characterisation of wind fields, while all other projects and landmarks are single-sited RIs. Remarkably, no ESFRI RIs exist for the important cross-cutting building blocks (cf. Figure 4) of energy systems integration and cross-sectional Energy R/s. 
The two ESFRI renewable energy (RE) RIs differ from the four other Rls by orders of magnitude when it comes to the expected capital costs. WindScanner and EU-SOLARIS have expected capital costs of around $€ 6$ million, IFMIF-DONES has an expected cost of $€ 420$ million, while the other three Rls have capital costs exceeding $€ 1$ billion (ESFRI, 2018: 16). In other words, construction costs run more than 100 times over for the largest single-sited RI compared to the only distributed RI. The RISCAPE-mapping identified similar conclusions outside Europe. The 'cheapest' RI in the dataset, Canadian wind RI WindEEE, suggested their construction costs as around $€ 30$ million, while expert estimations at Japan Atomic Energy Agency suggested capital values as large as $€ 100$ billion.

Overall, this is a notable finding with implications for the considerations of Research Infrastructures as a research policy tool. Identified Energy RIs inside and outside Europe are likely to be single-sited organizations with very high capital costs in proportions highly different from the make-up of energy research in general. By explicitly excluding commercial research, implicitly excluding research closer to market maturity, and by focusing more or less only on facilities set-up for long-time focus on single ",grand challenge" research question, the design of RIs is probably a bad fit to many ongoing energy research activities. This was also indicated through RISCAPE's workshops with European partners, where participants suggested preferences for agility, speed, and continuous relevance over long-term institutional commitments. For these organizations, variable geometries in research networks and collaborations may thus be preferable to institutionalized RI-status.

RISCAPE's mapping of the international RI landscape placed a particular emphasis of some organizational issues of special interest to the project's stakeholders. Some of these attributes reflected an original project focus, some stemmed from initial project findings, and some were explicitly suggested by project partners at the funding body, the European Commission. The selection of organizational aspects of interest therefore not only divulges new information on potential international partners but also highlights the mindset of the European RI community.

For the RISCAPE Energy domain, the first attribute mapped was the source of funding. The majority of interviewed RIs receive direct funding from respective federate governments. The Russian nuclear facility JSC State Scientific Centre Research Institute of Atomic Reactors (RIAR) is a stateowned joint-stock company (under ROSATOM), which no longer receives direct federal funding, but instead finances its activities through commercial contracts with Russian and international clients. These contracts are equivalent to multi-annual funding, as they run for periods up to 10 years. Interviewed RIs, with minor exceptions, all professed to have either statutes or a business plan. Operational time horizons extend significantly beyond traditional 3-5 year science projects, although financial time horizons might differ from the scientific facility planning. For example, two Brazilian Rls noted that although they are strategic RIs, there is no long-term financial commitment from the government. Funding decisions are instead negotiated yearly. This could make them a challenging partner to work with unless the European RIs are ready to embrace uncertainty.

Some international RIs have very broad research portfolios, and they are therefore difficult to compare with European RIs with a more focus. Complementarities are perhaps easiest to identify within nuclear research, where organizations are fewer, and the scientific purpose of each is more elaborated. For surveyed international RIs, access for external researchers varies. Some proclaim a $95 \%-100 \%$ access of their services available for external parties, while others only have facilities externally available less than $25 \%$ of the time. Some nuclear facilities limit certain types of access to internal personnel.

For decades, the principle that access to and sharing of data is essential to the conduct and advancement of science has been noted (Arzberger et al., 2004). Data policies have therefore become an important element of organizing research institutions, at least in Europe (Yu et al., 2017; Ryan, 2019). International Rls were also asked about data policies; however, this subject did not
Mapping forms and functions of particular interest 
Integration and internationalization potential

Methodological considerations for future mapping exercises raise the same kind of interest among the surveyed RIs, as it seemingly does among European Rls and European funding organizations.

External academic literature on Rls often focuses on evaluating impacts in terms of both scientific knowledge creation and socio-economic benefits. In particular, scientometric approaches have been applied (Del Bo, 2016; Carrazza et al., 2016; Qiao et al., 2016), although contributions of Research Infrastructures are often hard to trace through traditional measures of scientific progress such as bibliometrics, publication, and citation counts (Hallonsten, 2014a; Mayernik et al., 2017). With the recent 'fetishization of accountability' in science (Elzinga, 2012) costs, impacts, and benefits for the wider society are also measured. Investments in science, here in Research Infrastructures, are thus weighed against themselves, just like any other large public investment (Cló \& Florio, 2020). Today, a positive cost-benefit analysis (CBA) is necessary for Rls to gain access to European funds, and a CBA should be carried out in the preparatory phase of new ESFRI-projects. Studies show e.g. the economic impact of technological procurement at CERN (Castelnovo et al., 2018), the derived social benefits of large-scale RIs (Florio \& Sirtoti, 2016), or the technology transfer, spillover, and impact of entrepreneurship derived from them (Scarrá \& Piccaluga, 2020).

RISCAPE's responding RIs follows scientific impacts closely, either by the RI itself or by a third party (an almost even split among respondents). It is common to publish an annual report of the Rl's scientific achievements online. Socio-economic impact, however, is not followed to near the same degree among the responding RIs. An outlier is RIAR in Russia, which showcases its importance for the development of Dimitrovgrav City and the Ulyanovsk Region (the city and region, where its located). For RIAR, it is important to be able to attract talented scientists to the. The organization, therefore, publishes such regional data as local health of citizens, average salary, etc. This was one of the best examples in the study of a surprising best practice, which might inspire both European RI practitioners and academic observers of the field.

An important part of mapping was to identify potential opportunities for further collaborations with Europan entities. Many surveyed RIs already partake in collaborations with European researchers and organizations. Some respondents noted international organizations and initiatives - EUREKA, IAEA, Mission Innovation - as important for developing international partnerships. The international and joint initiatives generally seemed to be valued higher than initiatives based on European outreach.

A clear feature in interviews and other research was the pride many Energy RIs outside Europe held of their self-developed facilities (for example, in nuclear energy research), which can be served as complementary to the EU facilities. For example, China has become largely self-sufficient in reactor design and construction, and relative to the rest of the world, one of its major strengths is the nuclear supply chain. In South Korea, National Fusion Research Institute prides itself on having constructed the world-class fusion research device named KSTAR with domestic technology. It also gets involved in the ITER Korea Project, which has a long timeline until 2042 and beyond. At the same time, Rls generally express satisfaction with using technologies from the EU countries to improve their own facilities, and some of the non-EU RIs also attach great importance to the cooperation with the EU RIs.

Summarizing, we identified a great deal of interest in collaborating with European RIs, but conditional on the terms and interests of the surveyed organizations. Increasing collaborations with European partners is not an organizational priority in itself for non-European RIs.

As RISCAPE set out to map the unknown landscapes, we attempted to actively limit known biases and to uncover information in parts of the world the European research community was less familiar with. This quickly proved challenging. For example, for desk research and information gathering, a simple, but major methodological challenge was to look beyond only organizations with regularly updated English-language websites. Many large-scale organizations do not seem 
to put much effort into general communication outreach to English-speaking audiences, but perhaps instead find other avenues of reaching their scientific audiences.

Even with identification and contacts in order, linguistic and cultural challenges proved more notable than assumed at the outset of the project. For the energy domain mapping, we, therefore, added researchers with various local cultural and language skills to the team. Native-tongue interviews were eventually conducted in English, Russian, Chinese, and Brazilian. There was a clear tendency among the answers that more detailed answers were given in the respondent's mother tongue compared to when respondents were forced to respond in English. Some interviews were also conducted face-to-face with visits at the international facilities which provided the interviewer with a much richer understanding of the reality and environment of the surveyed Rl.

For similar, potential organizational mappings, it might therefore be suggested to put more emphasis on cultural and linguistic skills, and the ability to reach respondents within their natural environment. This would most likely be at a cost of more simplified and systematic cross-field data collection, but reward the examining researchers with richer and more informative results. Similarly, to enhance international RI collaboration, European organizations should probably be advised to be open to meeting different organizational, legal, linguistic, and budgetary frameworks even within the same 'global research scientific community' of their given fields.

This article presents the landscape analysis mapping of international Research Infrastructures (RIs) in the energy research domain, which was carried out as part of the Horizon 2020 RISCAPE-project. The article presented both how information was collected and reflections upon the process itself. We provide guidelines for how to define globally relevant Research Infrastructures, and how this question can be approached with the specific focus on the energy research field.

A lot of emphases is being put on RIs in European Union policy. This is also reflected by the allocation of hundreds of millions of euros annually of European funds, which are dedicated to supporting and developing RIs. Despite this strong policy preference for the concept, academic attention has been limited, and knowledge of the field outside the European Research Area almost non-existent. This article helps alleviate these dual issues with a particular focus on international energy research.

The global mapping reflected the definitional problems with categorizing RIs and the boundary issues which quickly arise when trying to identify RIs unique to the energy domain. The mapping also showed skewed distributions of the Energy Rls, which is suggested as an endemic feature of trying to squeeze the RI framework down on the energy research field: It disproportionally benefits specific types of single-sited institutions with large-scale construction costs. In Europe, funding for energy RIs is thus dominated by nuclear research institutions (1 ERIC, 2 ESFRI projects) and for a RI working with Carbon Capture and Storage (CCS, 1 ERIC). Renewable energy RIs exist on the ESFRI roadmap but at a scale of 100 times lower capital costs. Issues such as energy efficiency or smart energy distribution are not covered by Rls at all. The international mapping showed somewhat identical situations outside Europe as well. A notable finding of this article is therefore that there might arise a future paradox if European research policy simultaneously prioritizes Research Infrastructures as a favored research mechanism and seeks to prioritize the transition to non-nuclear sustainable energy as a forefront European grand challenge.

The article also showcases some of the organizational aspects, which the European RI-community stresses in its examination of international Research Infrastructures: Economical information, such as construction costs, annual budgets, and main sources of funding; legal frameworks, such as the existence of statutes; organizational policies, such as data policies and access policies; and scientific impact, including the ways the organizations themselves follow and measure these. Our mapping showed us that these lenses were indeed very 'European', and that 
a global RI-mapping will not result in answers to the above aspects within a few preselected choices. Instead, identified international RIs are very a very heterogeneous group. While potential for greater international Rl-collaboration was identified, openness to alternative organizational frameworks is therefore a necessity to harness the collaborative potential

Finally, our study provide insights on methodological improvements for future mapping exercises. Data collection proved to be much more efficient and rich when international, regional expertise was added to the research team. This should be considered also for future international landscape analyses, in which designing teams with a variety of linguistic and cultural skills might be more rewarding than designing teams with deep (but similar) knowledge of the scientific field under investigation.

Anderson, S. (2013). What are Research Infrastructures? International Journal of Humanities and Arts Computing, 7(1-2). https://doi.org/10.3366/ ijhac.2013.0078

Arzberger, P., Schroeder, P., Beaulieu, A., Bowker, G,, Casey, K., Laaksonen, L., Moorman, D., Uhlir, P. $\&$ Wouters, P. (2004). Promoting Access to Public Research Data for Scientific, Economic, and Social Development. Data Science Journal, 3, 135-152. https://doi.org.10.2481/dsj.3.135

Asmi, A., Sundet, J., Ryan, L., Salmon, E., Kubiak, C., Battaglia, S., Förster, M., Dupré, J., Walter, H., Stirling, W.G., Clausen, K., Knudsen, M., Ferreira-Aulu, M., Shabanova-Danielyan, E., Wang, W., Luukkanen, J., Kaivo-oja, J., Baldovin, C., Timmer, M., van der Meer, R., Vermeulen, R., Versic, I., Niccolucci, F., Sipos, G., \& Piscitelli, R. (2019). International Research Infrastructure Landscape 2019: A European Perspective. Brussels: European Commission. https:// doi.org/10.5281/zenodo.3539254

Beck, H.P. \& Charitos, P. (Eds.) (2021). The Economics of Big Science: Essays by Leading Scientists and Policymakers. Cham: Springer. https://doi. org/10.1007/978-3-030-52391-6

Biegelbauer, P., \& Weber, M. (2018). EU research, technological development and innovation policy. In Heinelt, H. \& Münch, S. (Eds.), Handbook of European Policies: Interpretive Approaches to the EU (pp. 241 259). Cheltenham: Edward Elgar Publishing Limited. https://doi.org/10.4337/9781784719364.00021

Caliari, T., Rapini, M. S., \& Chiarini, T. (2020). Research infrastructures in less developed countries: the Brazilian case. Scientometrics, 122, 451-475. https://doi.org/10.1007/s11192-019-03245-2

Carrazza, S., Ferrara, A., \& Salini, S. (2016). Research infrastructure in the LHC era: A scientometric approach. Technological Forecasting \& Social Change, 112, 121-133. https://doi.org/10.1016/j. techfore.2016.02.005

Castelnovo, P., Florio, M., Forte, S., Rossi, L., \& Sirtori, E. (2018). The economic impact of technological procurement for large-scale research infrastructures: Evidence from the Large Hadron Collider at CERN. Research Policy, 47(9), 1853-1867. https:// doi.org/10.1016/j.respol.2018.06.018

Clò, S., \& Florio, M. (2020). Science, innovation, and public services: editorial introduction. Journal of Economic Policy Reform, 23(1), 1-15. https://doi.or g/10.1080/17487870.2019.1649149

Cramer, K. C. (2020). A Political History of Big Science: The Other Europe. Cham: Palgrave MacMillan. https://doi.org/10.1007/978-3-030-50049-8

Cramer, K. C., \& Hallonsten, O. (2020). Big Science and Research Infrastructures in Europe. In Big Science and Research Infrastructures in Europe. Cheltenham: Edward Elgar Publishing Limited. https:// doi.org/10.4337/9781839100017

Cramer, K. C., Hallonsten, O., Bolliger, I. K., \& Griffiths, A. (2020). Big Science and Research Infrastructures in Europe: History and current trends. In Cramer, K. \& Hallonsten, O. (Eds.), Big Science and Research Infrastructures in Europe. Cheltenham: Edward Elgar Publishing Limited. https://doi. org/10.4337/9781839100017.00007

Department of Science and Technology (2016). South Africa Research Infrastructure Roadmap. Retrieved March 23, 2021, from https://www.dst.gov. za/images/Attachments/Department_of_Science_ and_Technology_SARIR_2016.pdf

D'Ippolito, B., \& Rüling, C. C. (2019). Research collaboration in Large Scale Research Infrastructures: Collaboration types and policy implications. Research Policy, 48(5), 1282-1296. https://doi.org/10.1016/j. respol.2019.01.011

Del Bo, C. F. (2016). The rate of return to investment in R\&D: The case of research infrastructures. Technological Forecasting and Social Change, 112, 26-37. https://doi.org/10.1016/j.techfore.2016.02.018

Elzinga, A. (2012). Features of the current science policy regime: Viewed in historical perspective. Science and Public Policy, 39(4), 416-428. https://doi. org/10.1093/scipol/scs046 
ESFRI (2018). Roadmap 2018: Strategy Report on Research Infrastructures. Retrieved March 23, 2021, from http://roadmap2018.esfri.eu/media/1066/esfri-roadmap-2018.pdf

European Commission (2020). Supporting the Transformative Impact of Research Infrastructures on European Research. Report of the High-Level Expert Group to Assess the Progress of ESFRI and Other World Class Research Infrastructures Towards Implementation and Long-Term Sustainability. Retrieved March 23, 2021, from https://op.europa.eu/en/publication-detail/-/ publication/310d694d-3f53-11 eb-b27b-01aa75ed71a1/language-en/format-PDF/source-180192378

Flatten, A. K. (2018). Global Research Infrastructures: A Decade of Science Diplomacy. Science $\&$ Diplomacy, 7(3).

Florio, M., \& Sirtori, E. (2016). Social benefits and costs of large scale research infrastructures. Technological Forecasting and Social Change, 112, 65-78. https://doi.org/10.1016/j.techfore.2015.11.024

Fortin, J.M. \& Currie, D.J. (2013). Big Science vs. Little Science: How Scientific Impact Scales with Funding. PLoS ONE. 8(6), e65263. https://doi.org/10.1371/ journal.pone.0065263

GSO (2017). Group of Senior Officials on Global Research Infrastructures. Progress Report 2017. Retrieved March 23, 2021, from http://www.gsogri.org/wp-content/uploads/2019/12/gso_progress_report_2017.pdf

Hallonsten, O. (2012). Continuity and change in the politics of european scientific collaboration. Journal of Contemporary European Research, 8(3), 301-318.

Hallonsten, 0. (2014a). How expensive is Big Science? Consequences of using simple publication counts in performance assessment of large scientific facilities. Scientometrics, 100, 483-496. https:// doi.org/10.1007/s11192-014-1249-z

Hallonsten, O. (2014b). The Politics of European Collaboration in Big Science. In Mayer, M. Carpes, R. \& Knoblich, R. (Eds.), The Global Politics of Science and Technology - Vol. 2. Heidelberg: Springer. https://doi. org/10.1007/978-3-642-55010-2_3

Hallonsten, 0. (2020). Research Infrastructures in Europe: The Hype and the Field. European Review, 28(4), 617-635. https://doi.org/10.1017/ $\mathrm{S} 1062798720000095$

Kaldewey, D. (2018). The Grand Challenges Discourse: Transforming Identity Work in Science and Science Policy. Minerva, 56, 161-182. https://doi. org/10.1007/s11024-017-9332-2

Leech, B. L. (2002). Asking Questions: Techniques for Semistructured Interviews. PS: Political Science and Politics. 35 (4): 665-668.
Lindstrøm, M. D., \& Kropp, K. (2017). Understanding the infrastructure of European research infrastructures-The case of the European Social Survey (ESS-ERIC). Science and Public Policy, 44(6), 855864. https://doi.org/10.1093/scipol/scx018

Mayernik, M. S., Hart, D. L., Maull, K. E., \& Weber, N. M. (2017). Assessing and tracing the outcomes and impact of research infrastructures. In Journal of the Association for Information Science and Technology, 68(6), 1341-1359. https://doi.org/10.1002/ asi.23721

MERIL (2020). MERIL - Mapping of the European Research Infrastructure Landscape. Portal retrieved March 23, 2021, from https://portal.meril.eu/meril/

Moedas, C. (2016). Science Diplomacy in the European Union. Science \& Diplomacy, 5(1).

Moskovko, M., Astvaldsson, A., \& Hallonsten, 0. (2019). Who is ERIC? The politics and jurisprudence of a governance tool for collaborative European research infrastructures. Journal of Contemporary European Research, 15(3). https://doi.org/10.30950/ jcer.v15i3.1028

Moskovko, M. (2020). Intensified role of the European Union? European Research Infrastructure Consortium as a legal framework for contemporary multinational research collaboration. In Cramer, K. \& Hallonsten, O. (Eds.), Big Science and Research Infrastructures in Europe. Cheltenham: Edward Elgar Publishing Limited. https://doi. org/10.4337/9781839100017.00012

Moskovko, M. \& Teich, A.H. (2020). Science Diplomacy in Action: European Collaboration and US Participation in Research Infrastructures. Science \& Diplomacy, 9(2).

OECD (2017). Strenthening the effectiveness and sustainability of international research infrastructures. Retrieved March 23, 2021, from https://www. oecd-ilibrary.org/science-and-technology/strengthening-the-effectiveness-and-sustainability-of-international-research-infrastructures_fal 1 a0e0-en

Papon, P. (2004). European scientific cooperation and research infrastructures: Past tendencies and future prospects. Minerva, 42, 61-76. https://doi. org/10.1023/B:MINE.0000017700.63978.4a

Papon, P. (2009). Intergovernmental cooperation in the making of European research. In European Science and Technology Policy: Towards Integration or Fragmentation? In Delanghe, H. , Muldur, U. \& Soete, L. (Eds.), European Science and Technology Policy - Towards Integration or Fragmentation. Cheltenham: Edward Elgar Publishing Limited. https://doi. org/10.4337/9781849803281.00010 
Prange-Gstöhl, H. (2017). The external engagement of the European Union in science and research: Towards EU science diplomacy?. In Damro, C., Gstöhl, S., \& Schunz, S. (Eds.), The European Union's Evolving External Engagement: Towards New Sectoral Diplomacies?. New York: Routledge. https://doi. org/10.4324/9781315169958-8

Prange-Gstöhl, H. (2019). The EU's Approach to Transatlantic Science and Research Relations: Between 'Laissez Faire' and 'Science Diplomacy'. European Foreign Affairs Review, 24, 81-98.

Qiao, L., Mu, R., \& Chen, K. (2016). Scientific effects of large research infrastructures in China. Technological Forecasting and Social Change, 112, 102-112. https://doi.org/10.1016/j.techfore.2016.07.029

Ryan, L. (2015). Governance of EU research policy: Charting forms of scientific democracy in the European research area. Science and Public Policy, 42(3), 300-314. https://doi.org/10.1093/scipol/scu047

\section{About the}

\section{KNUDSEN MIKKEL STEIN}

M.Sc.

Finland Futures Research Centre, Turku School of Economics, University of Turku

\section{Fields of interests}

Research infrastructures, technology foresight, innovation policy, futures studies.

\section{Address}

Rehtorinpellonkatu 3, 20014 Turun Yliopisto, Finland. Mikkel.knudsen@utu.fi

\section{KAIVO-0JA JARI}

Dr.

Finland Futures Research Centre, Turku School of Economics, University of Turku

\section{Fields of interests}

Futures studies, foresight, innovation, sustainability transitions, energy research.

\section{Address}

Rehtorinpellonkatu 3, 20014 Turun Yliopisto, Finland. jari.kaivo-oja@utu.fi
Ryan, L. (2015). Balancing Rights in the European Research Area: The Case of ERICs. European Intellectual Property Review, 41(4), 218-227. https://doi. org/10.1093/scipol/scu047

Scarrà, D., \& Piccaluga, A. (2020). The impact of technology transfer and knowledge spillover from Big Science: a literature review. In Technovation. In Press, available online. https://doi.org/10.1016/j. technovation.2020.102165

Xu, W., Xu, Y., \& Li, J. (2017). A study of RI clusters based on symbiosis theory. Sustainability, 9(3), 396. https://doi.org/10.3390/su9030396

Yu, H., Wested, J. B., Minssen, T. (2017). Innovation and intellectual property policies in European Research Infrastructure Consortia - Part 1: The Case of the European Spallation Source ERIC. Jornal of Intellectual Property Law \& Practice, 12(5), 384-397. https://doi.org/10.1093/jiplp/jpx022

\section{FERREIRA-AULU MARIANNA BIRMOSER}

\section{M.Sc.}

Finland Futures Research Centre, Turku School of Economics, University of Turku

\section{Fields of interests}

Futures studies, sustainability, international development.

\section{Address}

Rehtorinpellonkatu 3, 20014 Turun Yliopisto, Finland. marianna.b.ferreira-aulu@utu.fi

\section{LUUKKANEN JYRKI}

Dr.

Finland Futures Research Centre, Turku School of Economics, University of Turku

\section{Fields of interests}

Energy research, sustainability, renewable energy, energy foresight.

\section{Address}

Rehtorinpellonkatu 3, 20014 Turun Yliopisto, Finland. jyrki.luukkanen@utu.fi 